\title{
EDUKASI PERSIAPAN PEMBERIAN ASI EKSLUSIF TERHADAP SUAMI IBU HAMIL DENGAN MEDIA APLIKASI ONLINE BERBASIS ANDROID DI KELAS IBU HAMIL DESA MARGA AGUNG KEC JATI AGUNG KABUPATEN LAMPUNG SELATAN
}

\author{
Yeyen Putriana ${ }^{1^{*}}$, Risneni $^{2}$ \\ ${ }^{1 *}$ Poltekkes Tanjungkarang Jurusan Kebidanan Prodi Sarjana Terapan Kebidanan \\ Tanjungkarang \\ Email Korespondensi:yeyenputriana@gmail.com,risneni.1962@gmail.com
}

\begin{abstract}
ABSTRAK
Kegiatan Pengabdian Masyarakat yang dilaksanakan di kelas Ibu Desa Marga Agung yang merupakan kelas ibu di wilayah kerja desa Marga agung kec Jatiagung Kabu LampugnSelatan , yang dilaksanakan pada tanggal 9 April 2021 yang berfokus pada suami lbu-ibu hamil yang tinggal berada di desa Marga Agung Kec Jati Agung . kegiatan ini bertujuan untuk mensosialisasikan Aplikasi online berbasis android tentang asi ekslusif di Kelas Ibu Desa Marga Agung yang berada di tengah Desa Marga Agung Kec Jati Agung Kabupaten Lampung Selatan.

Tujuan kegiatan ini adalah meningkatkan seluruh pengetahuan suami ibu hami dan ibu hamil sendiiri tentang persiapan pemberian asi esklusif selama kehamilan. Kegiatan menyusui adalah proses pemberian asi yang memakan waktu yang lama . minimal 2 tahun. Tentunya diperlukan persiapan yang matang selama masa hamil. Jika ibu hamil tidak mempersiapkan pemberian asi ekslusif maka tingginnya risiko kejadian gagalnya asi ekslusif dan menyusui selama 2 tahun . keberhasilan pemberian asi ekslusif dan menyusui selama 2 tahun terbukti diperlukan dukungan dari keluarga terutama suami. Suami sebagai pengambil keputusan dalam keluarga seklaigus sebagai support system dari seorang ibu menyusui mempunyai peran penting dalam keberhasilan menyusui. Untuk itu diperlukan wawasan dari suami ibu hamil apa saja yang harus dipersiapkan selama kehamilan.dan bentuk-bentuk dukungan kepada istri selama menyusui . dukungan ini akan meningkatkan rasa percaya diri seorang ibu selama menyusui. Setelah dilakukan sosialisasi aplikasi diberikan juga penyuluhan PHBS dalam rangka pencegahan covid 19.

Pelaksanaan pengabdian masyarakat berjalan dengan lancar, sosialisai aplikasi berjalan lancar dengan mematuhi protocol kesehatan . kegiatan sosialiasi aplikasi dan penuluhan PHBS telah dilaksanakan di kelas ibu hamil di Balai desa Marga Agung Kec Jati Agung Kab Lampung selatan
\end{abstract}

Kata kunci : Aplikasi, Edukasi, Kehamilan, Persiapan ASi,

\section{ABSTRACT}

Community Service activities carried out in the Marga Agung Village Mother class which is a mother class in the working area of the Marga Agung village, Jatiagung district, South Lampung district, which was held on April 9, 2021, which focused on the husbands of pregnant women who live in the village of Marga Agung, Jati sub-district. Great . This activity aims to socialize an Android-based online application about exclusive breastfeeding in the Marga Agung Village Mother Class which is in the middle of Marga Agung Village, Jati Agung District, South Lampung Regency. 
The purpose of this activity is to increase all knowledge of pregnant women's husbands and pregnant women themselves about the preparation for exclusive breastfeeding during pregnancy. Breastfeeding is a process of giving breast milk that takes a long time. minimum 2 years. Of course, careful preparation is needed during pregnancy. If pregnant women do not prepare for exclusive breastfeeding, there is a high risk of failure of exclusive breastfeeding and breastfeeding for 2 years. The success of exclusive breastfeeding and breastfeeding for 2 years is proven to require support from the family, especially the husband. The husband as a decision maker in the family as well as the support system of a breastfeeding mother has an important role in the success of breastfeeding. For this reason, insight is needed from the husband of pregnant women, what should be prepared during pregnancy, and forms of support for the wife during breastfeeding. This support will increase a mother's self-confidence during breastfeeding. After the socialization of the application, PHBS counseling was also given in the context of preventing covid 19.

The implementation of community service went smoothly, application socialization went smoothly by complying with the health protocol. Application socialization activities and PHBS counseling have been carried out in the class of pregnant women at the Marga Agung village hall, Jati Agung district, South Lampung regency.

Keywords: Application, Education, Pregnancy, Breastfeeding Preparation,

\section{PENDAHULUAN}

Pemberian ASI Eksklusif dapat mengurangi tingkat kematian bayi di Indonesia. ASI Eksklusif mendapat dilegitimasi dalam Undang-Undang Republik Indonesia Nomor 36 Tahun 2009 tentang Kesehatan, Peraturan Pemerintah Nomor 33 Tahun 2012 tentang Pemberian ASI Eksklusif, Surat Keputusan Menteri Kesehatan Nomor 450/Menkes/SK/IV/2004 tentang Pemberian ASI secara Eksklusif, dan Peraturan Daerah Provinsi Sulawesi Selatan Nomor 6 tahun 2010 tentang ASI Eksklusif. Meskipun ASI Ekslusif sudah diketahui manfaat dan dampaknya serta menjadi amanat konstitusi, namun kecendrungan pada ibu untuk menyusui bayi secara eksklusif masih rendah.

Rendahnya pemberian ASI Eksklusif oleh ibu menyusui di Indonesia disebabkan oleh faktor internal dan eksternal. Faktor internal meliputi rendahnya pengetahuan dan sikap ibu, dan faktor eksternal meliputi kurangnya dukungan keluarga, masyarakat, petugas kesehatan maupun pemerintah, gencarnya promosi susu formula, faktor sosial budaya serta kurangnya ketersediaan fasilitas pelayanan kesehatan ibu dan anak.

Para pemangku kepentingan bidang kesehatan menyimpulkan bahwa sebab dasar rendahnya cakupan ASI Eksklusif adalah akses bayi terhadap ASI Eksklusif yang rendah. Akses yang rendah tersebut sangat dipengaruhi oleh potensi spesifik ibu sebagai figur utama, yaitu perilaku ibu. Hasil kajian beberapa variabel dalam kaitannya dengan perilaku ibu menyimpulkan bahwa pengetahuan, sikap, dan kepercayaan berpengaruh terhadap keputusan. 
Suami merupakan orang terdekat ibu yang banyak mempunyai peran pada masa kehamilan, persalinan, dan setelah bayi dilahirkan. Dukungan suami didapatkan dari tersil terhadap delapan pertanyaan dengan pengategorian antara lain: kurang, cukup, dan baik. Hasil penelitian menunjukkan bahwa ada hubungan antara dukungan suami menunjukkan bahwa ibu yang mendapatkan dukungan secara baik oleh suami sebagian besar melakukan pemberian ASI secara eksklusif yaitu sebesar 93,8\%, sedangkan ibu yang mendapatkan kurang dukungan sebagian besar menyusui bayinya dengan tidak eksklusif.

Sebagian besar bentuk dukungan yang diberikan suami kepada ibu saat pemberian ASI adalah suami membantu merawat bayi dan suami membantu menyelesaikan pekerjaan rumah tangga, sedangkan bentuk dukungan yang paling sedikit dilakukan suami adalah memberi tahu memberi tahu informasi tentang pentingnya ASI, suami menyarankan tidak memberikan makanan/minuman pada bayi sebelum umur 6 bulan, suami memberikan pujian kepada ibu karena menyusui, suami membantu merawat bayi seperti menggendong, mengganti popok bayi, bermain dengan bayi dan merawat kakak bayi, suami membantu menyelesaikan pekerjaan rumah tangga, suami membantu memecahkan masalah dalam pemberian ASI, suami menyediakan uang tambahan untuk keperluan ibu pada saat menyusui, dan suami menyediakan makanan bergizi yang dibutuhkan oleh ibu pada saat pemberian ASI.

Untuk itu diperlukan pemberian edukasi kepada suami tentang dukungan yang diperlukan oleh istri selama menyusui. Pemberian edukasi selama ini terhambat dikarenakan ibu hamil sering periksa ke puskesmas maupun posyandu tanpa di damping oleh suaminya. Dengan alasan suami sedang bekerja mencari nafkah. Pengunduhan aplikasi online berbasis android ini merupakan salah satu cara agar suami mendapatkan edukasi tanpa harus terganggu pekerjaanya. Suami dapat membaca materi tentang persiapan pemberian asi di masa kehamilan. Agar pada saat masa menyusui sedikitnya sudah mempunya gambaran apa yang dapat dikerjakan dalam mendukung istri yang sedang menyusui . hasil akhir yang diharapkan dengan meningkatnya pengetahuan suami, dukungan terhadap istri menyusui juga meningkat sehingga capain asi ekslusif selama 6 bulan dapat berhasil serta menyusui selama 2 tahun dapat terlaksana .

\section{MASALAH}

Suami ibu hamil belum pernah mendapatkan penyuluhan khusus mengenai persiapan pemberian ASI melalui aplikasi online .

\section{METODE}

a. Tujuan Persiapan

Diawali dengan penyusuan proposal dan persiapan materi yang merupakan hasil Penelitian dari dosen prodi Sarjana Terapan Kebidanan

b. Pelaksanaan

Pelaksanaan kegiatan di Balai desa Marga Agung pada hari jum at tgl 9 April 2021. Dengan dihadiri lebih dari 30 ibu hamil .dengan pelaksanaan 
menggunkan protocol kesehatan pencegahan covid. Dengan berbagai metode yaitu : diawali tentang tata cara pengunduhan aplikasi melalui WhatsApp, dan play store. Kemudian dijelaskan tentang isi aplikasi baik materi maupun tata cara mengisi aplikasi sesuai identitas diri. Penjelasan tentang materi aplikasi dengan protokol kesehatan covid 19 yaitu ; menjaga jarak, memakai masker dan mencuci tangan sebelum dan sesudah kegiatan. Evaluasi ditanyakan secara langsung, dengan hasil $100 \%$ ibu hamil mengerti tentang materi yang telah diberikan dan memahi cara membuka aplikasi online

\section{HASIL DAN PEMBAHASAN}

Peningkatan pengetahuan masyarakat merupakan bagian dari tugas sebagai petugas kesehatan . termasuk persiapan pemberian asi . mengingat sedang terejadi pendemi covid maka lebih optimal penyuluhan melalui aplikasi online. Untuk mencegah bertanu dan berkumpul dalam satu tempat.

\section{SIMPULAN}

Pemberian asi ekslusif maupun selama 2 tahun memerlukan persiapan sejak masa kehamilan. Untuk itu diperlukan perispan baiii dari ibu hamil amupun dari suami ibu hamil yang merupakan support system yang penting dalam mendukung ibu selama proses menyusui

\section{DAFTAR PUSTAKA}

Aleda Florice oyay. Agus Sartono, Erma Handarsari, 2020. Dukungan Ibu Kandung, Mertua dan Suami Dengan Praktek ASI Eklsusif (0-6 Bulan) di Kampung Sereh Wilayah Puskesmas Sentani Papua. Jurnal Gizi Vol 9 n0 1 (2020) Fakultas Ilmu Keperawatan dan Kesehatan Universitas Muhammadiyah Semarang.

Budianto FH dan Handayani OW K .2017. Aplikasi Android "ayah ASI" Terhadap peran ASI dalam pemberian asi ekslusif (Breastfeeding Father). Jurnal unnes.ac.id. Volume 2 no 1.

Faizah, Dina , 2013. Gerakan Nasional Sadar Gizi pada Seribu Hari Pertama Kehidupan: Saatnya Memanfaatkan Teknologi Mobile dan Internet. Jurnal Ilmiah mahasiswa Kedokteran Indonesia 2.

Deningsih S dan, Hakim N 2020. Pengaruh Metode Ceramah dan Metode Aplikasi Berbasis Android Terhadap Pengetahuan Kesehatan Reproduksi Remaja. ejurnalmalahayai.ac.id. vol 6 nomor 4.

D.Wahyuningsih 2013 , Dukungan suami dalam asi ekslusif. Jurnal Keperawatan Maternitas, 2013 - jurnal.unimus.ac.id

Elma Nindi Larasati. 2019, Gambaran Dukungan Suami dalam Pemberian ASI Esklusif di Desa Balun dan Desa Sukoanyar Ke. Turi. Kabupaten Lamongan. Unnair.ac.id 
Evi, Kaderani Barutu, Alit Gunawan I made, Aritonang Irianto, 2019. Intervensi Booklet dalam Pemberian ASI Terhadap Pengetahuan Tentang ASI pada Suami Di Dusun Jetis Desa Widodomartani. Poltekkesjogja.ac.id.

Hapsari, D.I., dan Taufik, M. 2018. Hubungan antara pengetahuan ibu, perawatan payudara, penyuluhan asi ekslusif, dukungan keluarga dan dukungan petugas kesehatan dengan pemberian asi ekslusif di wilayah kerja puskesmas pandan kecamatan sungani tebelian kabupaten sintang. Jurnal kesehatan masyrakat khatulistiwa.5.(l). 1-7

Indriyani Bakri, Merry Meta Sari, Fenti Dwi Pertiwi, 2019. Hubungan Dukungan Suami dengan Pemberian ASI Ekslusif di Wilayah Kerja Puskesmas Sempur, Kota Bogor, tersedia di ejournal.uika.ac.id

IP Hasanah, TS Nindya, 2016, Kontribusi Inisiasi Menyusui Dini dan Dukungan Suami pada Riwayat asi Ekslusif bayi Umur 6 sampai 12 bulan . tersedia di ejournal.unair.ac.ids

Irfa Eka Agraresti, Ahmad Sauqi, 2016, Faktor -faktor yang berhubungan dengan kegagalan pemberian ASI ekslusif di Kabupaten Semarang. Journal of Nutritional College, volume 5 no 4 (2016)

Kartika, V.M.,Astuti .FP., Isfaizah. 2017. Hubungan Dukungan Keluarga dengan Keberhasilan Pemberian asi Eklusif pada Ibu Bekerja di Wilayah Kerja Puskesmas Beringin Kabupaten Semarang. Jurnal Komunikasi Kesehatan .8 (1).62-68

Murya, Yosef, 2014. Pemrograman Android Black Box, Jasakom ISBN 978979-1090

Muhammad Nur Hidayat, 2017. Hubungan Tingkat Pengetahuan Suami Tentang ASI esklusif dengan dukungan suami dalam pemberian ASI ekslusif di Puskesmas Bantul 1 Yogyakarta. Tersedia di http: //repository.unjaya.ac.id.

Notoatmojo, Soekidjo, 2012. Ilmu Kesehatan Masyarakat Teori dan Aplikasi, Jakarta: Rineke Cipta.

Roesli, Utami, 2005. Mengenal ASI Esklusif. Jakarta. Trubus Agriwidya . 